\title{
De A Sesta do sr Abade: análise crítica
}

\author{
Lídia Maria Machado* \\ Escola Superior de Educação de Bragança \\ Bragança, Portugal \\ Recebido em: 06/05/2019 \\ Aceito em: 25/o7/2019
}

Resumo: Em A Velhice do Padre Eterno, ocupar-se-á o presente estudo dos elementos lexicais que remetem para a luz e sua simbologia sobretudo no poema "A Sesta do sr Abade", tendo em conta a origem geográfica de Guerra Junqueiro. Procurar-se-á perceber o laço com Freixo de Espada à Cinta presente na poesia do autor, com o seu pensamento e a filosofia de vida através da análise do poema.

Palavras-chave: Guerra Junqueiro. Poesia. Luz. Pensamento.

\begin{abstract}
In the book $A$ Velhice do Padre Eterno this study will be focused on the lexical elements that remind us light as well as their symbology mainly in the poem "A Sesta do sr Abade", taking into account the geographical origin of Guerra Junqueiro. It will be tried to understand the bond with Freixo de Espada à Cinta present in the author's poetry, with his way of thinking and life philosophy while the poem is being read and analysed.
\end{abstract}

Key-words: Guerra Junqueiro. Poetry. Light. Thought.

Resumen: En el libro A Velhice do Padre Eterno se ocupará el presente estudio de los elementos lexicales que nos remiten para la luz y su simbología sobre todo en el poema "A Sesta do sr Abade", teniendo en cuenta el origen geográfico de Guerra Junqueiro. Se buscará percibir el lazo con Freixo de Espada à Cinta presente en la poesía del autor, en su pensamiento y filosofía de vida a través del análisis del poema.

Palabras clave: Guerra Junqueiro. Poesía. Luz. Pensamiento. 


\section{Introdução}

Guerra Junqueiro. Muito se tem falado do homem inteligente, ativo na política, na vida e na literatura. O vitivinicultor e o lavrador, o pai e o colecionador, o homem não conformado com os cenários que o rodeava e, por isso, muitas vezes, considerado anticlerical, embora a sua colecção de arte religiosa claramente manifestasse o contrário. Como afirma Gama (1997, p. 1), Guerra Junqueiro foi o "agitado e agitador, reflexivo e motivador de reflexões, lutador por grandes causas e por combates menores, hipercrítico, gerador de grandes amigos e seguidores e alvo de ataques impenitentes”. Em suma, - parece-nos justo afirmar —, Guerra Junqueiro é o homem poliedro que terá lido milhares de livros em busca da Verdade ${ }^{1}$; o rapaz que saiu da sua aldeia, ainda muito novo e que sempre guardou no fundo do seu ser a saudade desse tempo feliz e tão expressa no poema "Regresso ao Lar".

Por tudo isto, é possível encontrar entre a sua imensa biblioteca títulos como Le Christianisme Médiévalet Moderne de Charles Guigrebert ou Jesus et la Tradition Évangélique de Alfred Loisy ou ainda Le Christianisme Antique de Charles Guignebert.

É preciso dizer também que a sua obra foi produzida num clima de grande controvérsia religiosa e de grande instabilidade política e social. Sobre o primeiro aspeto há que mencionar a publicação da encíclica Syllabus, ou seja, o índice publicado pelo Papa Pio IX juntamente com a Bula de 1864, constituído por 80 doutrinas que a Igreja católica excomungava literalmente - o que, naturalmente, deu origem a um abismo entre a Fé e a Razão e deu a entender que ambas eram antagónicas.

É todo este clima - finais do século XIX e princípios do XX, que

\footnotetext{
${ }^{1}$ Segundo as palavras de Guerra Junqueiro: "Bem, Beleza e Verdade: eis as três qualidades manifestadas respectivamente nas obras do herói, do artista e do filósofo. Cada uma delas revela uma face de Deus e todas juntas revelam a totalidade de Deus - como Ser Bom, Belo e Verdadeiro" (SOUSA, 2002, p. 258).
} 
marcou o estar-no-mundo não só de Junqueiro, mas de outros como Antero de Quental, Sampaio Bruno, Gomes Leal, Ramalho Ortigão [...]. Segundo o autor era "o problema da mentalidade portuguesa que estava em causa [...] a intencionalidade da construção de uma «vida nova»" (GAMA, 1997, p. 4).

Ora, tal como nos é dado a saber,

sendo o elemento religioso um dos fundamentais da cultura, estes homens perceberam que para proceder à sua modificação, era necessário intervir num dos seus pilares fundamentais, precisamente o da forma como era praticada a religião (GAMA, 1997, p. 4).

É, pois, nesta situação, diríamos, profundamente dramática, que se produz a obra de Guerra Junqueiro e é também neste clima que, em 1885, vem a público, em fascículos, a obra A Velhice do Padre Eterno, cuja edição de 1967 consultaremos neste trabalho.

Trata-se de uma obra considerada, por muitos críticos literários (por exemplo: Sousa (2002); Carvalho (1998); Coimbra (1996); Franco (1996); Garção (1978), injuriosa, até de péssimo gosto, concebida contra todos os aspetos promulgados pela Igreja Católica. Contudo, e ao contrário do que se possa depreender das palavras do autor e do homem, Junqueiro assume-se muitas vezes, ao logo do seu percurso literário, social e político com um forte sentido de Deus. Leiam-se a propósito as palavras de Junqueiro citadas por Camilo Castelo Branco num estudo de 1886 ,

\footnotetext{
“Terei os anos de vida necessários para escrever esse livro? Não sei; no entanto rogo a Deus do fundo da minha alma que me deixe terminar com um hino de esperança e de harmonia uma batalha de cóleras e sarcasmos"), bem como a análise de Camilo a tais palavras, "aqui temos, pois, um ateu que crê em Deus e na imortalidade da alma; crê na bemaventurança para os bons e nas penas eternas para os maus; pede a Deus a sua divina compaixão para os que padecem e para os que delinquiram; um ateu, finalmente, que recorre do fundo da sua alma a Deus pedindolhe vida para concluir a sua obra" (JUNQUEIRO, 1967, p. XI).
}

Mas não só Camilo se refere ao cerne da obra como o próprio autor. No entender de Junqueiro (1921, p. 12-13) A Velhice do Padre Eterno é "um livro da mocidade [...] cheio ainda dum racionalismo desvairador, um racionalismo de 
ignorância, estreito e superficial"; é um livro "mau, e muitas vezes abominável" e prossegue cimentando o seu pensamento profundamente religioso, "no catolicismo existem absurdos, mas no âmago da sua doutrina resplandecem verdades fundamentais, verdades eternas, as verdades de Deus". É, portanto, um livro fruto das vivências do autor enquanto ser social e atento no final do século XIX em Portugal e, acreditamos, não poderia ser outro.

A que se devem, questionar-nos-íamos, poemas como A Sesta do sr Abade (JUNQUEIRO, 1967, p. 157-174)? Atendendo ao contexto político e religioso de então e à análise da sua obra como um todo, bem como ao seu percurso como homem do seu tempo, arriscaríamos a dizer que Junqueiro entendia que a Igreja católica não estaria a servir a pureza essencial da pregação cristã. Por exemplo, no poema "Resposta ao Syllabus", a contestação perante a postura da Igreja do seu tempo é clara, mas também em obras de outros autores como Alexandre Herculano e Eça de Queirós se percebe que as verdades estabelecidas pela Igreja, até no plano filosófico, não se coadunavam com o sentimento que Junqueiro possuía da Revelação Cristã. Contudo, afirmar Junqueiro um semita será no entender de Pereira (2017, p. 211), "deduzi-lo por aparências ou evidências da sua fisionomia, pela análise dos seus gestos e atitudes, por testemunhos orais do próprio e de terceiros ou ainda por indícios internos da sua obra".

Assim sendo, o trabalho que nos propomos apresentar tem como objetivo único proceder a um levantamento e análise dos elementos lexicais ligados à luz que revestem o poema A Sesta do sr Abade presente em A Velhice do Padre Eterno, tomando como ponto de referência a origem geográfica do poeta Guerra Junqueiro - a vila de Freixo de Espada à Cinta, conhecida pelos recortes montanhosos do rio Douro, pelo vinho produzido nas suas encostas douradas pelo Sol, pelos frutos secos como a amêndoa e o azeite. O poema será o mote para se procurarem elementos ligados à luz e sua simbologia, tendo em conta não só a origem do autor, mas também o seu pensamento religioso (aliás já discutido anteriormente) e filosofia de vida.

Através da análise do poema promover-se-á uma discussão em torno dos elementos que no poema rementem para a luz, as referências temporais, a ironia 
inerente ao trabalho árduo da personagem Abade, as comparações abundantes entre o sol escaldante de verão, a vida pacata dessa personagem e a vida miserável da população, na "aldeia morta/ A terra, esquálida e funérea,/ Em lugar das canções da abundância e do amor" (JUNQUEIRO, 1967, p.157-174). Dessa forma, propomos uma reflexão no sentido de pensar discursivamente Guerra Junqueiro o anticlerical, o contestatário, através da poesia, o contestatário eterno tal como o título da sua obra indica. Ou, por outro lado, um contestatário profundamente consciente "da moral do catolicismo" (JUNQUEIRO, 1921, p.12-13)?

\section{A Sesta do sr Abade}

Sem qualquer tentativa de estabelecer uma ligação entre um pequeno poema oriundo da infância de Junqueiro e o poema A Sesta do sr Abade, não poderíamos, no entanto, deixar de o citar por nos parecer de interesse relevante atendendo às semelhanças que, claramente, acontecem. Trata-se de uma quadra singela, fruto, ao que parece, de um momento lúdico entre o jovem Junqueiro e os seus colegas de escola primária na pacata vila de Freixo de Espada à Cinta, depois de terem sabido da suposta festança em que o professor, também pároco, se teria envolvido no dia anterior: "Se o mar fosse de vinho,/ E a terra toda um folar,/ O nosso professorinho/ Comia a terra e bebia o mar" (PEREIRA, 2017, p. 212).

A imagem jocosa a que então o jovem Guerra Junqueiro estabelecera do pároco e também seu professor é, só por si, semelhante à imagem que, muitos anos mais tarde, se viria a refletir na personagem Abade de A Sesta do sr Abade. Uma personagem que, num "ilimitado incêndio abrasador" de fome, dor, doença, agonia, em que não há lume no lar, nem pão nos armários" e onde os olhares da "Morte,/ a hiena magra e vesga, espreita a um canto/ Um berço onde agoniza um anjo", se destaca por ser detentora de uma "estância idílica e tranquila” de cuja adega "Sai um aroma intenso e rico de bom vinho./ O abade é beberrão/", e da qual sai também uma "frescura, que asseio e que néctar". O sujeito poético fornece-nos, 
pois, todo um conjunto de características que revestem a casa e a vida confortável do Abade que contrastam com o modus vivendi da população em profunda agonia e sem qualquer perspetiva em relação ao futuro.

Se o leitor continuar a acompanhar o diálogo do sujeito poético e a sua aparente visita guiada pelos vários compartimentos da casa do Abade enquanto este dorme a sesta ("Mas subamos depressa enquanto o abade orneia" (JUNQUEIRO, 1967, p. 163), os contrastes entre o meio-dia na aldeia silenciosa e triste e a sua casa persistem. Vejamos. Na rua os mendigos arrastam-se, dementes e cobertos de chagas; a terra surge esquálida e funérea; as fontes secaram-se, os montes estão nus e "os rebanhos são como um pulular de vermes", mas no interior da casa do Abade "pedem belas maçãs camoesas rubicundas,/ Cachos d'uvas ainda a rir, peras-marmelas,/ Encaixilhando tudo com à volta com morcelas" (JUNQUEIRO, 1967, p. 165).

E o Abade continua a sua sesta sonora - um sono solto de quem por nada mais parece ansiar a não ser o conforto de lençóis "duma finura extrema" e a libertar os aromas do alecrim e da alfazema e a certeza de que o alimento diário abunda na sala e na adega, nas "malgas com marmelada" e "nos frascos com compotas”. Ao contrário do que seria expectável dadas as funções do Abade, ao Criador inaudito "agonizando aflito" é dedicada uma "banca ordinária e simples de estudante" e ao "breviário exótico" / [...] mais cebo e traça que latim" (JUNQUEIRO, 1967, p. 165). O representante de Deus na Terra é, portanto, apresentado como alguém dado aos prazeres da carne e do ócio.

Eis, então, que o leitor, acompanhado pelo sujeito poético, chega à alcova onde dorme o "hipopótamo" num "catre disforme" no qual "cabiam nesse vasto enxergão, à vontade,/ A preguiça dum porco e a luxúria dum frade” (JUNQUEIRO, 1967, p. 167) caracterizado como um "sórdido animal" que "tem cerdas na cabeça e nas orelhas tojo"; "ruge como um trovão, silva como um apito" no meio de uma imensa satisfação de quem é bafejado por um sonho durante o qual é clamado num “cortejo de glória” (JUNQUEIRO, 1967, p. 167).

Não nos referiremos à paródia que é criada em torno desse sonho. $\mathrm{Na}$ verdade, parece-nos na sua essência um texto criado muito à semelhança da sátira

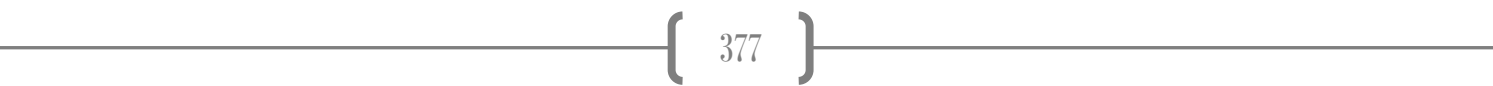


criada em torno de $A$ Velhice do Padre Eterno. A redação de A Velhice da Madre Eterna é

\begin{abstract}
a sociedade actual com todos os ridículos, com todos os seus vícios, com todos os seus conselheiros de pechisbeque, com todos os seus jornalistas para rir, como todas as suas apoteoses truanescas. Este livro é filho do seu tempo - de tudo ri e de tudo troça. E quando a espaços, põe de parte a gargalhada juvenalesca e agarra no tagante huguesco, a indignação espirra por todos os lados, laivada de sangue espumante e quente (PEREIRA, 1998, p. 19).
\end{abstract}

Através da paródia se satirizam costumes, política, religião, sociedade. E não será A Velhice do Padre Eterno isso mesmo: uma longa sátira aos costumes da Igreja Católica? Não será a atitude impávida da figura do Abade uma sátira perante uma população em desespero pela falta de condições básicas enquanto ele, pároco, rejubila de prazer na sua cama de sesta? Não será a forma de tratamento "sr. Abade" que, noutras circunstâncias denotaria respeito, inteligência, bondade, instrução, uma imensa sátira, sobretudo, se atentarmos a recursos expressivos como a ironia e a comparação bem patentes ao longo do poema que nos remetem para um paralelo entre as condições de vida do povo da aldeia e o calor implacável; a terra seca e infértil e a fome como se a população, de alguma forma, fosse castigada pela falta de compaixão e desleixo deliberado do seu pároco? O Abade é o anti-herói / uma espécie de opositor, uma vez que o herói, nas palavras de Junqueiro, "sacrifica a sua alma ao recolher em si as dores alheias - daqueles que sofrem, e sacrifica o seu corpo dando a sua própria vida para as consolar" (SOUSA, 2002, p. 259-268). A personagem de A Sesta do sr Abade faz parte do conjunto das "almas medíocres e superficiais", ou seja, "os simplesmente homens que, tal como os animais, se satisfazem com o mundo transitório das aparências e dos fenómenos" e cuja alma “zela apenas pela satisfação das necessidades do corpo", tal como Junqueiro afirma (SOUSA, 2002, p. 259-268). 


\section{Simbologia da luz}

Os elementos que em A Sesta do sr Abade remetem para a luz e sua simbologia são, na realidade, uma constante nos trabalhos de Guerra Junqueiro, na sua filosofia de vida e no seu pensamento religioso que, naturalmente, são considerados indissociáveis. Segundo o autor (que estabelece uma diferença clara entre "os grandes homens" e os "simplesmente homens"), os grandes homens

com obras de luz sulcam a noite para iluminar o caminho que o rebanho deverá seguir na sua viagem que o conduz finalmente à Luz Plena. Esta viagem da Noite para a Luz, da Terra para o Céu, é uma viagem de libertação da dor e do sofrimento e de conquista plena do amor infinito de Deus (SOUSA, 2002, p. 257).

No poema, contudo, a referência à luz é, efetivamente, uma constante não como um elemento de bem-estar físico e psicológico, mas como um elemento que acrescenta ainda mais sofrimento a uma população faminta e degradada pela doença.

O poema, uma longa descrição que o sujeito poético parece presenciar de perto, inicia-se ao meio-dia quando o sol já "flameja”, implacável num "murmúrio abrasador de luz" como "um grande forno" que atrai, consequentemente, um “mosqueiro febril” e a aridez própria dos lugares áridos e povoados por cobras onde as árvores estão "sequiosas" e o "ar carboniza”. Trata-se de um lugar abandonado por Deus onde nem sequer "passa a nódoa aérea duma asa”, os bois anseiam por pasto, os "velhos aldeões" estão "minados pelas febres"; um lugar incendiado pela “cólera de Deus, cujo olhar incendeia”, mas onde "os círios noite e dia/ Alumiam a branca imagem de Maria” na esperança de uma bênção. No entanto, segundo o sujeito poético, observador omnipresente, todas as preces são em vão. O sol "morre congestionado" para, na manhã seguinte, surgir de novo "cáustico, a chamejar, como um remorso ardente".

Tal como se percebe, os elementos de luz, sol, calor, presentes no poema em vez de remeterem para ideias de abundância, paz, esperança, prosperidade, lazer, 
surgem com um efeito totalmente oposto e denotam pobreza extrema que, ironicamente, se mistura com tentativas inglórias de salvação através do acender dos círios, do sofrimento extremo da população, a sua degradação flagrante perante um total abandono daquele que deveria zelar pelo bem-estar espiritual do seu rebanho, mas que simplesmente dorme (perante um povo em agonia). A pacatez que se observa na aldeia não é apenas fruto do excesso de calor, mas fruto da desistência de viver, quer das pessoas, quer dos animais; da miséria em que todos mergulharam e em que a única companhia das crianças parece ser uma vara de porcos.

As questões sociais, religiosas e até de ordem política levantadas pelo poema representam, sem dúvida, os grandes temas pelos quais se debateu Guerra Junqueiro na luta antimonárquica e anticlerical que encetou; uma luta na qual "a boçalidade de Igreja cujos membros são apresentados como criaturas ignorantes e sensuais guiando as massas atrasadas à maneira de rebanhos" (JÚDICE, 1981, p. 1314).

\section{Considerações finais}

Tendo em conta a exposição que elaboramos em torno do ambiente da aldeia a desvanecer-se debaixo de um sol escaldante e o contraste gerado através da descrição da figura, diríamos insultuosa, do Abade e da respectiva casa - fresca, perfumada, abastada e recatada - não se torna difícil, no nosso entender, estabelecer um laço entre a figura criada pelo poeta enquanto criança, e num momento de inocente brincadeira, e a figura do Abade. Contudo, e apesar de $A$ Velhice do Padre Eterno ser considerada uma obra que mesmo antes de ter sido publicada já despertava nos leitores toda uma corrente anticlerical pelo seu conteúdo profundamente contestatário para com a Igreja católica e as suas práticas e as práticas e atitudes dos seus mais diretos seguidores, tal como a personagem 
Abade, acreditamos que seria exagerado dizer que Guerra Junqueiro deu seguimento à ideia que já o perseguia desde criança.

Parece-nos, no entanto, importante deixar a nota de que, efetivamente, o espaço descrito no poema que serviu a nossa crítica é um espaço em evidente degradação tal como a mentalidade do pároco responsável pelas almas que o habitam. Tendo como pano de fundo a bibliografia consultada, não nos parece de modo algum descabido afirmar que o espaço em A Sesta do sr. Abade não é mais do que uma metáfora do estado do país ao nível social, religioso e político; um hino ao pessimismo nacional também transversal às obras dos autores contemporâneos de Junqueiro, como por exemplo os intelectuais da Geração de 70.

Numa tentativa de darmos resposta à questão que nos surgiu acima antes de iniciarmos a análise do poema de Junqueiro, não nos parece estarmos perante um Guerra Junqueiro apenas profundamente anticlerical e contestatário, mas um homem intimamente consciente das questões mais prementes do seu tempo, sociais, políticas e religiosas, para quem "o mundo é um processo evolutivo, cujo telos é Deus" e, por isso, "dada a sua proximidade essencial a Deus, os grandes homens são, no fundo, mediadores de deus que conduzem os simplesmente homens até Ele" (SOUSA, 2002, p. 256).

\section{Referências}

CARVALHO, Amorim de. Guerra Junqueiro e a sua Obra Poética: Análise Crítica. Porto: Lello Editores, 1998.

COIMBRA, Leonardo. Guerra Junqueiro. Porto: Lello Editores, 1996.

FRANCO, António Cândido. A Epopeia Pós-Camoniana de Guerra Junqueiro. Lisboa: Gazeta do Mundo de Língua Portuguesa, 1996.

GAMA, Manuel. O sagrado e o religioso em Guerra Junqueiro. In: Colóquio Guerra Junqueiro e a Modernidade, Centro Regional do Porto da Universidade Católica Portuguesa, 3 e 4 Janeiro 1997. 
GARÇÃO, Mayer. Junqueiro republicano. In: JUNQUEIRO, Guerra - Horas de Combate, Porto: Lello \& Irmão Editores, 1978.

JÚDICE, Nuno. Poesia de Guerra Junqueiro. Seara Nova/ Editorial Comunicação, 1981.

JUNQUEIRO, Abílio Guerra. A Velhice do Padre Eterno (com um estudo de Camilo Castelo Branco). Porto: Lello\& Irmão Editores, 1967. Prosas Dispersas, Porto: Livraria Chardon, 1921.

PEREIRA, Henrique Manuel. Guerra junqueiro e as paródias: A velhice da Madre Eterna. Humanística e Teologia, 19, 1998. Raízes de um cristianismo exacerbado: o anticlericalismo de Junqueiro. Revista Lusófona de Ciência das Religiões, 20, 2017.

SOUSA, Joaquim Saraiva de. Junqueiro: Poesia e Filosofia. Humanística e Teologia, Porto, n.. 24, p. 256-268, 2002.

\footnotetext{
* Doutoramento em Didática das Línguas pela Universidade de Vigo, Espanha. Professora Adjunta Convidada do Departamento de Português da Escola Superior de Educação de Bragança, Portugal.
} 